\title{
Chromosomal Aberrations in Monozygotic and Dizygotic Twins Versus Singletons in Denmark During 1968-2009
}

\author{
Lone Kroeldrup, ${ }^{1,2}$ Lisbeth A. Larsen, ${ }^{3}$ Christina Fagerberg, ${ }^{1}$ Jens M. Hertz, ${ }^{1,4}$ \\ and Kaare Christensen $1,3,4$ \\ ${ }^{1}$ Department of Clinical Genetics, Odense University Hospital, Odense C, Denmark \\ ${ }^{2}$ Department of Clinical Research, University of Southern Denmark, Odense C, Denmark \\ ${ }^{3}$ Epidemiology, Biostatistics and Biodemography, Department of Public Health, Faculty of Health Science, University of \\ Southern Denmark, Odense C, Denmark \\ ${ }^{4}$ Human Genetics, Department of Clinical Research, University of Southern Denmark, Odense C, Denmark
}

\begin{abstract}
Background: Hall (Embryologic development and monozygotic twinning. Acta Geneticae Medicae et Gemellologiae, Vol. 45, 1996, pp. 53-57) hypothesized that chromosomal aberrations can lead to monozygotic (MZ) twinning. However, twinning and chromosomal aberrations increase prenatal mortality and could reduce the prevalence of chromosomal aberrations in live-born twins. We compared prevalence proportion ratios (PPR) of chromosomal aberrations and trisomy 21 (T21) in live-born twins versus singletons born in Denmark during 1968-2009. Methods: We linked the Danish Twin Registry and a 5\% random sample of all singletons to the Danish Cytogenetic Central Register and calculated PPR adjusted for maternal age for $M Z$, dizygotic (DZ), and all twins versus singletons. Zygosity was based on questionnaires or genetic markers. Results: No overall difference in risk of chromosomal aberrations or T21 in twins versus singletons was found. PPR in MZ and DZ twins was 0.87 (95\% $\mathrm{Cl}[0.60,1.27])$ and $1.05(95 \% \mathrm{Cl}[0.88,1.27])$, respectively. For T21 there was a tendency to a lower prevalence in $\mathrm{MZ}$ twins compared to singletons (PPR: 0.29, $95 \% \mathrm{Cl}[0.07,1.14])$, whereas PPR was significantly increased in DZ twins $(1.62,95 \% \mathrm{Cl}[1.20,2.19])$. The observed proportion of $\mathrm{MZ}$ twin pairs among twin pairs with aberrations $(0.22,95 \% \mathrm{Cl}[0.16,0.28])$ was significantly lower than the proportion expected from the Weinberg method $(0.32,95 \% \mathrm{Cl}[\mathrm{Cl}, 0.26,0.39])$. Conclusion: Based on databases providing complete national coverage on twins with chromosomal aberrations, we found no overall difference in risk of chromosomal aberrations or T21 in twins versus singletons. Around conception twins may have an increased risk of chromosomal aberrations, but loss of especially $M Z$ embryos could lead to similar risk among live-born twins and singletons.
\end{abstract}

Keywords: twins, zygote, chromosomal aberration, trisomy 21

Based on a number of case reports on monozygotic (MZ) twins discordant for genetic conditions (Hall, 1996; Machin, 1996; Zwijnenburg et al., 2010), Hall hypothesized in 1996 (Hall, 1996; Hall \& Lopez-Rangel, 1996) that MZ twinning could be caused by a genetic event in the zygote after fertilization. Hall argued that a wide range of genetic and epigenetic events could cause polarization of two genetically dissimilar cell clones and ultimately lead to cleavage (Hall, 2003). As a consequence of the hypothesis, MZ twins should be expected to be discordant for genetic aberrations, either completely or in a mosaic state. Additionally, a larger proportion of MZ twin embryos should have genetic aberrations compared to dizygotic (DZ) twins and singletons.
Epidemiological studies on twins with genetic aberrations are sparse. In older studies on the prevalence of congenital malformations in twins, the prevalence of twins with trisomy 21 (T21) was lower than in singletons, with a particularly low prevalence in same-sex (SS) twins in some

RECEIVEd 12 November 2016; ACCEPTED 22 February 2017 ADDRESS FOR CORRESPONDENCE: Lone Kroeldrup, Department of Clinical Genetics, Odense University Hospital, J.B. Winsløws Vej 4, DK-5000 Odense C, Denmark. E-mail: lone.kroeldrup@rsyd.dk 
studies (Doyle et al., 1991; Hay \& Wehrung, 1970; Kallen, 1986; Windham \& Bjerkedal, 1984). The number of twins with T21 included in these studies was small, however, only between 10 and 56 individuals. In a study from 1964 (McDonald, 1964), data on 67 pairs of twins with T21 were collected, among which only five SS concordant pairs were found (vs. 30 SS discordant pairs). Assuming that nearly all $\mathrm{MZ}$ pairs are concordant, the authors concluded that this implied a significant deficiency of MZ twins with T21 in the cohort, and suggested that one mechanism could be a reduced viability in utero, if one or both twins had T21 or a more severe chromosomal disorder. Three more recent register-based studies (Glinianaia et al., 2008; Li et al., 2003; Tang et al., 2006) on malformations in twin pregnancies or live-born twins included 21, 46, and 48 individuals with chromosomal disorders and found that twins and singletons were at similar risk for chromosomal disorders such as trisomy 13,18 , and 21. In a comprehensive European study from 2013, Boyle et al. (2013) found a lower risk of chromosomal disorders in twins compared to singletons. In a subsequent, larger study on relative risk of T21 in multiple pregnancies, Boyle et al. (2014) concluded that individual fetuses from multiple pregnancies had an overall reduced risk of T21. They also concluded that the maternal age-specific risk of T21 in MZ and DZ versus singleton pregnancies was lower than expected, particularly in MZ twins. However, a general weakness of the study was the indirect assessment of zygosity by use of the Weinberg rule (Fellman \& Eriksson, 2006).

It is well established that both chromosomal aberrations and twinning influence pregnancy outcome. More than $50 \%$ of clinically recognized first trimester pregnancy losses show a chromosomal abnormality, with T21 being one of the more common (Goddijn \& Leschot, 2000; Hassold \& Jacobs, 1984; Ljunger et al., 2005; Simpson, 2007). Furthermore, pre- and perinatal loss rate is significantly higher in twin pregnancies (Rydhstroem \& Heraib, 2001), particularly in MZ twins, primarily due to structural malformations and vascular complications such as twin-twin transfusion syndrome (D’Antonio et al., 2013; Glinianaia et al., 2008; Oldenburg et al., 2012). It is plausible that a combination of these conditions could add an additional risk of pregnancy loss.

To summarize, the prevalence of chromosomal aberrations in twins at birth could differ from that in singletons for several reasons. It may be higher, according to the Hall hypothesis, if a chromosomal aberration can cause MZ twinning, or it may be lower if the combination of twinning and a chromosomal aberration raises the risk of fetal death synergistically.

The aim of this study was to determine the occurrence of chromosomal aberrations among all live-born twins in Denmark during 1968-2009 and, furthermore, to compare the prevalence of chromosomal aberrations in twins versus singletons.

\section{Materials and Methods}

\section{Data Sources}

The study included all live-born twins and a 5\% random sample of all live-born singletons born in Denmark during April 2, 1968 to December 31, 2009 and was based on linkage between the Danish Civil Registration System, the Danish Twin Registry, and the Danish Cytogenetic Central Register, supplemented by linkage to the Danish Newborn Screening Biobank (NBS-Biobank) at the Danish Statens Serum Institute (SSI) and the National Patient Registry.

Danish Civil Registration System. This includes individuals alive and resident in Denmark for at least one day from April 2, 1968. A personal identification number (CPRnumber) enables linkage to all other national registers (Pedersen, 2011).

Danish Twin Registry (DTR). This is a national register established in 1953, containing more than 86,000 twin pairs born in Denmark since 1870. Twins have been ascertained using different methods previously described (Harvald et al., 2004; Skytthe et al., 2002; Skytthe et al., 2011). Ascertainment of zygosity was mainly questionnaire based, a method with less than 5\% misclassification (Christiansen et al., 2003), while a minor fraction underwent DNA-based zygosity analyses at various occasions. At present, zygosity data based on questionnaires have been compiled up through 2000. SS twins were classified as MZ, SS-DZ, and unknown zygosity (UZ), that is, no answer to questionnaire or not yet questioned. Opposite sex (OS) twins were classified as DZ.

Danish Cytogenetic Central Register (DCCR). This is a national register established in 1968, which is considered to have complete ascertainment of all prenatal and postnatal chromosome examinations carried out in Denmark since April 2, 1968 (Videbech \& Nielsen, 1979).

Danish Newborn Screening Biobank (NBS-Biobank). This biobank is part of SSI, an institute under the Danish Ministry of Health. Since December 31, 1981, the NBSBiobank has stored surplus blood sample material from newborns in Denmark who are all tested for a number of inborn errors of metabolism by analyzing a blood sample desiccated on filter paper (Norgaard-Pedersen \& Hougaard, 2007). DNA from filter paper was used to determine zygosity status in a subset of twin pairs.

National Patient Registry (NPR). The NPR has recorded nationwide information on all somatic hospital admissions since 1977. Since 1995, data on outpatients and emergency patients have been included as well (Lynge et al., 2011). By linking twins to the NPR, the health status of co-twins with no cytogenetic report was estimated and used as a proxy for their karyotype (i.e., normal/abnormal). 


\section{Karyotypes}

Twins and singletons with chromosomal aberrations were identified by linking DTR twin data (using the Danish Civil Registration System) to the DCCR and by linking data from a 5\% random sample of singletons from the Danish population and the DCCR, respectively.

The DCCR gave access to all postnatal karyotypes registered as aberrations and subsequent to information regarding co-twins (i.e., whether they had a normal karyotype or no cytogenetic report).

We subdivided aberrant karyotypes provided from the DCCR into abnormal, benign variants (i.e., well-known variants with no known phenotypical influence, listed in Appendix A) and normal (i.e., co-twins only). Individuals with no evidence of chromosomal aberrations with the karyotypes 46,XX and 46,XY were considered to have a normal karyotype even if their phenotypic sex did not correspond to their sex chromosomes.

\section{Zygosity Determination Based on DNA Examinations}

DNA-based examinations were carried out in SS twin pairs with chromosomal aberrations. DNA was provided by the NBS-Biobank at the SSI. Samples were only available for twins born after December 31, 1981(79 pairs). Zygosity was determined with 12 microsatellite markers (listed in Appendix B) using a 4-capillary ABI-3130 Genetic Analyzer (Applied Biosystems, Foster City, CA, USA) and GeneMarker v. 2.4.0 analysis software. MZ twins had at least 11 informative, identical markers. DZ twins had at least three informative, non-identical markers. The probability of monozygosity determined by identity in all markers was estimated by computational methods (Sieberts et al., 2002) to be at least $0.998 \%$.

\section{Statistical Analyses}

Statistical analyses were performed using STATA version 14.1(Statacorp LP, TX, USA).

Calculations of unadjusted prevalence proportion ratios (PPR) with 95\% confidence intervals of all twins, SS twins, and OS twins versus singletons were carried out for the period 1968-2009. All PPR values for twins were calculated using twin individuals (i.e., not twin pairs) versus singletons. As maternal age was unknown in a fraction of singleton mothers, unadjusted PPR without this fraction was calculated. Data were stratified on maternal age groups ( $<25,25-29,30-34,35-39$, $>39$ years), and PPR indirectly standardized for maternal age (using mothers of singletons as reference) was calculated. PPR analyses were repeated on data without karyotypes considered to be benign variants. A logistic regression model adjusting for maternal age groups as well as birth cohorts (1968-1974, and hereafter in 5-year periods until 2005-2009) was carried out.

PPR for MZ twins, DZ twins (i.e., SS-DZ twins + OS twins) and UZ twins versus singletons was specified for the period of 1968-2000, since zygosity status for the entire twin cohort (i.e., questionnaire-based) was available only up through 2000).

Corresponding analyses including only individuals with T21 were carried out.

\section{Analyses in Twin Pairs in Which at Least One Had a Chromosomal Aberration}

Probandwise concordance rates (regarding karyotype) were calculated (with and without benign variants) as (2.concordant pairs)/([2.concordant pairs] + discordant pairs) (McGue, 1992). Discordant twins were defined as having any of the following combinations of karyotypes: aberration/normal, aberration/no karyotype or two different aberrations. Concordant twins had identical karyotypes.

Calculation of the expected proportion of $\mathrm{MZ}$ and $\mathrm{DZ}$ pairs according to the Weinberg method (Fellman \& Eriksson, 2006) was performed, in which the number of DZ pairs (i.e., SS-DZ + OS) equals two times the number of OS pairs, and the number of $M Z$ pairs equals all pairs minus $D Z$ pairs. Subsequently, the expected proportion of MZ and DZ twins was compared to the observed proportion.

Hospital admission profiles of pairs in which only one twin had T21 were studied in order to estimate health status of co-twins without cytogenetic reports. Using admission data from NPR we analyzed time to first hospitalization (after the age of 90 days, to avoid concomitant hospitalization of healthy, newborn co-twins). To exclude potential bias from OS co-twins (supposedly healthy, as T21 is a de novo event in > 95\%; Gardner et al., 2012) analyses were repeated using only SS co-twins.

\section{Results}

Prevalence Proportion Ratios in Twins and Singletons With Chromosomal Aberrations

A total of 75,135 live-born twins born in Denmark from April 2, 1968 to December 31, 2009 were included in the study. Of these, $234(0.31 \%)$ had a chromosomal aberration. The corresponding number in a $5 \%$ random sample of live-born singletons in the Danish population was 400 of $129,088(0.31 \%)$. Unadjusted PPR was 1.01 (95\% CI [0.86, $1.18]$ ) or 1.02 if using only singletons with known maternal age. Unadjusted PPR results are shown in Table 1.

As maternal age is a potential confounder known to influence the frequency of twinning (Abel \& Kruger, 2012) as well as chromosomal aberrations (Hassold \& Chiu, 1985; Hassold \& Jacobs, 1984), data were stratified on maternal age groups (Table 1).

Nearly identical prevalence of chromosomal aberrations among twins versus singletons was found, except for a tendency of an increase in the prevalence among twins in the maternal age group of 35-39 years. Another potential confounder is birth year, which is positively associated with twin birth (Herskind et al., 2013) and influences the 


\section{TABLE 1}

Unadjusted Prevalence Proportion Ratios (Overall and Stratified in Maternal Age Groups) for Twin Individuals Versus Singletons With Chromosomal Aberrations (Benign Variants Included) Born 1968-2009

\begin{tabular}{|c|c|c|c|c|c|}
\hline & \multicolumn{2}{|c|}{ Singletons } & \multicolumn{2}{|r|}{ Twins } & \multirow[b]{2}{*}{$\begin{array}{l}\text { Unadjusted PPR } \\
{[95 \% \mathrm{Cl}]}\end{array}$} \\
\hline & Total & $\begin{array}{l}\text { Chromosomal } \\
\text { aberrations (\%) }\end{array}$ & Total & $\begin{array}{l}\text { Chromosomal } \\
\text { aberrations }^{\mathrm{a}}(\%)\end{array}$ & \\
\hline Unknown maternal age included & 129,088 & $400(0.31)$ & 75,135 & $234(0.31)$ & $1.01[0.86,1.18]$ \\
\hline $\begin{array}{l}\text { Unknown maternal age excluded } \\
\text { Stratified by maternal age }\end{array}$ & 128,591 & $391(0.30)$ & 75,135 & $234(0.31)$ & $1.02[0.87,1.20]$ \\
\hline$<25$ & 35,088 & $108(0.31)$ & 11,686 & $32(0.27)$ & $0.89[0.60,1.32]$ \\
\hline $25-29$ & 47,973 & $131(0.27)$ & 25,074 & $57(0.23)$ & $0.83[0.61,1.14]$ \\
\hline $30-34$ & 32,442 & $97(0.30)$ & 25,993 & $76(0.29)$ & $0.98[0.72,1.32]$ \\
\hline $35-39$ & 11,184 & $39(0.35)$ & 10,899 & $57(0.52)$ & $1.50[1.00,2.25]^{\star}$ \\
\hline$>39$ & 1,904 & $16(0.84)$ & 1,483 & $12(0.81)$ & $0.96[0.46,2.03]$ \\
\hline Unknown & 497 & $9(1.81)$ & 0 & 0 & \\
\hline
\end{tabular}

Note: ${ }^{a}$ Individuals with chromosomal aberrations. $* p=.049$.

number of children diagnosed with chromosomal aberrations as well (Ekelund et al., 2008).

Figure 1(a) shows the relation between twins versus singletons with a chromosomal aberration as a function of birth period. A significant difference $(p<.001)$ between singletons (12 of 15,$270 ; 0.08 \%$ ) and twins (37 of 13,699 twins; $0.27 \%$ ) born with chromosomal aberrations was seen in the last period (2005-2009), while there was no significant difference between twins and singletons in other birth periods.

The PPR for all twins versus singletons adjusted for maternal age was 1.01 (95\% CI $[0.89,1.15])$. An overview of PPR results can be seen in Table 2. Taking birth period as well as maternal age into account in a logistic regression did not change the overall risk estimate (OR: $1.02 ; 95 \%$ CI $[0.86,1.21])$, that is, no difference in prevalence of chromosomal aberrations between twins and singletons was found.

When stratifying by SS and OS twins, adjusted PPR did not differ significantly from twins overall (Table 2), nor did the odds ratio when birth period and maternal age were taken into account (data not shown).

Exclusion of karyotypes considered to be benign variants, that is, reducing the sample to 320 of $400(80 \%)$ singletons and 195 of 234 (83\%) twins, did not influence the results substantially (data not shown).

PPR results stratified by zygosity can be seen in Table 2 . The fraction of MZ and DZ twin pairs with DNA-based zygosity used in PPR calculations for $\mathrm{MZ}$ and $\mathrm{DZ}$ twins was $65 \%$ and $57 \%$, respectively. In the remaining pairs, zygosity was determined based on questionnaires.

In MZ twins, the prevalence of chromosomal aberrations was 28 of 9,629 $(0.29 \%)$ and the corresponding, adjusted PPR compared to singletons was 0.87 (95\% CI $[0.60,1.27]$ ). In DZ twins, adjusted PPR was 1.05 (95\% CI $[0.88,1.27]$ ). For DZ twins, the PPR was significantly higher in SS-DZ twins than in singletons, whereas in OS twins it was significantly lower (Table 2). Exclusion of karyotypes considered to be benign variants did not influence the results substantially (data not shown).

\section{Prevalence Proportion Ratios in Twins and Singletons With Trisomy 21}

Analyses were repeated for individuals with T21. Results are shown in Table 3. Among 75,135 twins, 75 individuals $(0.10 \%)$ had T21. The corresponding number in the sample of singletons was 92 of 129,088 (0.07\%). Unadjusted PPR was $1.40(95 \% \mathrm{CI}[1.03,1.90])$ and 1.49 (95\% CI [1.10, 2.03]) if using only singletons with known maternal age. PPR adjusted for maternal age was 1.31 (95\% CI [1.05, 1.64]), whereas the odds ratio taking birth period into account as well was 1.33 (95\% CI $[0.97,1.82]$ ).

In data stratified by maternal age groups, we found a significantly increased risk for twins in the maternal age of 3539 years (PPR: 2.22; 95\% CI [1.12, 4.40]), and no difference between twins and singletons in other age groups (data not shown). Figure 1(b) shows the relation between live-born twins versus singletons with T21 as a function of birth period. A borderline significant difference $(p=.043)$ was seen in twins, 11 of 13,699 twins $(0.08 \%)$, versus singletons, 4 of $15,270(0.03 \%)$, with T21 in the last period (2005-2009).

PPR in Twins With Trisomy 21, Stratified by Zygosity. The results of PPR calculations for individuals with T21 stratified into $\mathrm{MZ}$ and $\mathrm{DZ}$ twins versus singletons are shown in Table 3. The prevalence of MZ twins with T21 was very low in our cohort (adjusted PPR: 0.29, 95\% CI [0.07, 1.14]). In contrast, a significantly increased risk of T21 in DZ twins was observed, as adjusted PPR was 1.62, (95\% CI [1.20, 2.19]).

\section{Analyses of Twin Pairs in Which at Least One Had a Chromosomal Aberration}

A total of 206 twin pairs with chromosomal aberrations were included in the study, hereof 70 OS, $28 \mathrm{MZ}$, 91 SSDZ, and 17 UZ pairs. Among the co-twins, 41 (20\%) had a 


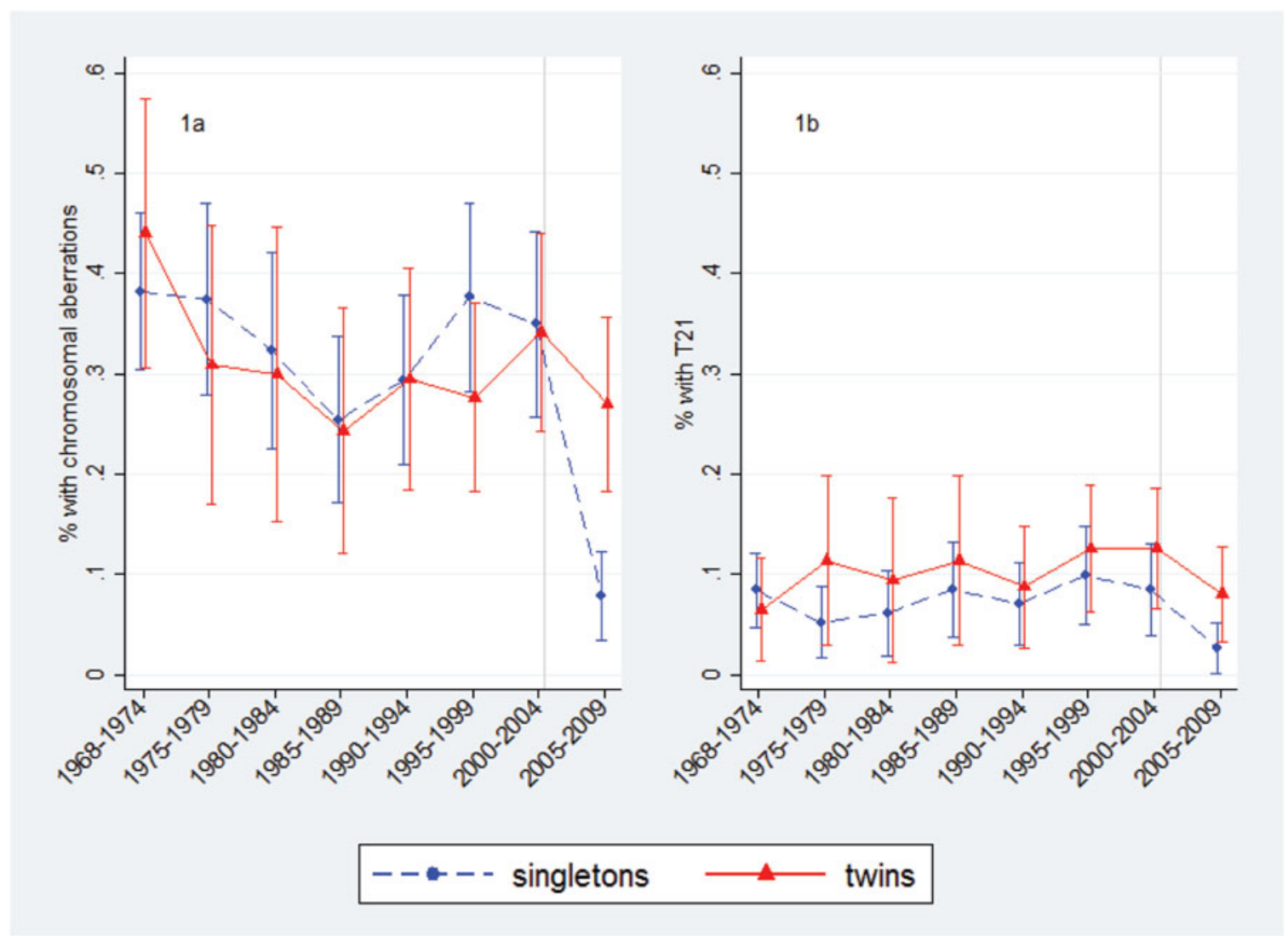

\section{FIGURE 1}

(Colour online) Fraction (\%) of live born children with chromosomal aberrations, benign variants included (1a) and trisomy 21 (1b), respectively, among twins $(n=75,135)$ and singletons $(n=129,088)$ in our cohort, as a function of birth period. The vertical grey line indicates the introduction of a new screening method for trisomy 13, 18, and 21 in September 2004 (Ekelund et al., 2008).

TABLE 2

Prevalence Proportion Ratios (Unadjusted and Adjusted for Maternal Age) for Twin Individuals Versus Singletons With Chromosomal Aberrations

\begin{tabular}{|c|c|c|c|c|}
\hline & Total & $\begin{array}{l}\text { Chromosomal } \\
\text { aberrations }^{a}(\%)\end{array}$ & $\begin{array}{l}\text { Unadjusted PPR } \\
{[95 \% \mathrm{Cl}]}\end{array}$ & $\begin{array}{l}\text { Adjusted PPR } \\
{[95 \% \mathrm{Cl}]}\end{array}$ \\
\hline \multicolumn{5}{|l|}{ Year of birth: 1968-2009 } \\
\hline All singletons & 129,088 & $400(0,31)$ & & \\
\hline Singletons with known maternal age & 128,591 & $391(0.30)$ & & \\
\hline All twins & 75,135 & $234(0.31)$ & $1.02[0.87,1.20]$ & $1.01[0.89,1.14]$ \\
\hline SS twins & 48,953 & $159(0.33)$ & $1.07[0.89,1.28]$ & $1.06[0.91,1.24]$ \\
\hline OS twins & 26,182 & $75(0.29)$ & $0.94[0.74,1.21]$ & $0.92[0.73,1.15]$ \\
\hline \multicolumn{5}{|c|}{ Stratification by zygosity. Year of birth: $1968-2000^{d}$} \\
\hline All singletons & 101,459 & $345(0.34)$ & & \\
\hline Singletons with known maternal age & 100,993 & $336(0.33)$ & & \\
\hline All twins & 50,552 & $162(0.32)$ & $0.96[0.80,1.16]$ & $0.93[0.80,1.09]$ \\
\hline SS twins & 33,944 & $119(0.35)$ & $1.05[0.86,1.30]$ & $1.03[0.86,1.23]$ \\
\hline OS twins & 16,608 & $43(0.26)$ & $0.78[0.57,1.07]$ & $0.74[0.55,0.99]$ \\
\hline MZ twins & 9,629 & $28(0.29)$ & $0.87[0.59,1.28]$ & $0.87[0.60,1.26]$ \\
\hline DZ twins & 30,783 & $113(0.37)$ & $1.10[0.89,1.36]$ & $1.05[0.87,1.26]$ \\
\hline SS-DZ twins & 14,175 & $70(0.49)$ & $1.48[1.15,1.92]$ & $1.43[1.13,1.80]$ \\
\hline UZ twins & 10,140 & $21(0.21)$ & $0.62[0.40,0.97]$ & $0.61[0.40,0.93]$ \\
\hline
\end{tabular}

Note: SS = same-sex; OS = opposite sex; MZ = monozygotic; DZ = all dizygotic (i.e., same-sex and opposite sex); SS-DZ = same-sex dizygotic; UZ = uncertain zygosity.

andividuals with a chromosomal aberration.

${ }^{b}$ Reference: singletons with known maternal age.

${ }^{\mathrm{c}}$ Adjusted for maternal age.

'Stratification by zygosity is shown for birth years 1968-2000, as zygosity data based on questionnaires have been compiled up through 2000. 
TABLE 3

Prevalence Proportion Ratios (Unadjusted and Adjusted for Maternal Age) for Twin Individuals Versus Singletons With Trisomy 21

\begin{tabular}{|c|c|c|c|c|}
\hline & Total & Trisomy $21^{a}(\%)$ & $\begin{array}{l}\text { Unadjusted PPR } \\
{[95 \% \mathrm{Cl}]}\end{array}$ & $\begin{array}{l}\text { Adjusted PPR } \\
{[95 \% \mathrm{Cl}]}\end{array}$ \\
\hline \multicolumn{5}{|l|}{ Year of birth: 1968-2009 } \\
\hline All singletons & 129,088 & $92(0.07)$ & & \\
\hline Singletons with known maternal age & 128,591 & $86(0.07)$ & & \\
\hline All twins & 75,135 & $75(0.10)$ & $1.49[1.10,2.03]$ & $1.31[1.05,1.64]$ \\
\hline SS twins & 48,953 & $45(0.09)$ & $1.37[0.96,1.97]$ & $1.25[0.93,1.67]$ \\
\hline OS twins & 26,182 & $30(0.12)$ & $1.71[1.13,2.60]$ & $1.41[0.99,2.02]$ \\
\hline \multicolumn{5}{|c|}{ Stratification by zygosity. Year of birth: $1968-2000^{d}$} \\
\hline All singletons & 101,459 & $79(0.08)$ & & \\
\hline Singletons with known maternal age & 100,993 & $73(0.07)$ & & \\
\hline All twins & 50,552 & $53(0.11)$ & $1.45[1.02,2.07]$ & $1.30[0.99,1.70]$ \\
\hline SS twins & 33,944 & $35(0.10)$ & $1.43[0.95,2.13]$ & $1.32[0.95,1.84]$ \\
\hline OS twins & 16,608 & $18(0.11)$ & $1.50[0.90,2.51]$ & $1.26[0.79,1.99]$ \\
\hline MZ twins & 9,629 & $*$ & $0.29[0.07,1.17]$ & $0.29[0.07,1.14]$ \\
\hline DZ twins & 30,783 & $42(0.14)$ & $1.89[1.29,2.76]$ & $1.62[1.20,2.19]$ \\
\hline SS-DZ twins & 14,175 & $24(0.17)$ & $2.34[1.48,3.71]$ & $2.06[1.38,3.08]$ \\
\hline UZ twins & 10,104 & $9(0.09)$ & $1.23[0.61,2.45]$ & $1.14[0.59,2.19]$ \\
\hline \multicolumn{5}{|c|}{$\begin{array}{l}\text { Note: } \mathrm{SS}=\text { same-sex; OS = opposite sex; } \mathrm{MZ}=\text { monozygotic; } \mathrm{DZ}=\text { all dizygotic (i.e., same-sex and opposite sex); } \mathrm{SS}-\mathrm{DZ}=\text { same-sex } \\
\text { dizygotic; } \mathrm{UZ}=\text { uncertain zygosity. } \\
\text { andividuals with trisomy } 21 . \\
{ }^{\mathrm{b}} \text { Reference: singletons with known maternal age. } \\
{ }^{\mathrm{c}} \text { Adjusted for maternal age. } \\
{ }^{\mathrm{d}} \text { Stratification by zygosity is shown for birth years } 1968-2000 \text {, as zygosity data based on questionnaires have been compiled up } \\
\text { through 2000. *Not reported due to small numbers. }\end{array}$} \\
\hline
\end{tabular}

normal karyotype, 28 (14\%) had an abnormal karyotype, and $137(66 \%)$ had no cytogenetic report.

Table 4 provides a detailed overview of zygosity determined by questionnaires and subsequent DNA-based zygosity examinations as well as concordance status with regard to karyotype. Questionnaire-based zygosity information was supplemented by DNA examinations in 84 of 136 SS pairs (62\%) (Table 4).

Concordance Rates. The probandwise concordance rate was $0.76(95 \%$ CI $[0.60,0.87])$ for MZ, 0.02 (95\% CI [0.00, $0.07])$ for $\mathrm{DZ}$ and 0.38 (95\% CI $[0.18,0.62])$ for UZ twins.

\section{Expected and Observed Proportions of $M Z$ and $D Z$} Twins. The observed distribution of zygosity among the 206 pairs was $28 \mathrm{MZ}$, 91 SS-DZ, $17 \mathrm{UZ}$, and 70 OS pairs. The expected number of SS-DZ pairs, according to Weinberg's rule, should be 70 (i.e., number of OS pairs $=$ number of SS-DZ pairs), that is, a total of $140(70+70) \mathrm{DZ}$ pairs. If we omitted the 17 UZ pairs, this would leave 189 pairs to be considered. The zygosity of the remaining pairs (189 - 140 $=49$ ) would then be MZ. In summary, the observed proportion of MZ pairs was $(28 / 189)=0.15(95 \%$ CI $[0.10,0.21])$, whereas the expected proportion of MZ pairs was (49/189) $=0.26(95 \% \mathrm{CI}[0.20-0.33]), p$ value $<.01$, showing that we did not observe the expected proportion of MZ pairs.

If we also included the $17 \mathrm{UZ}$ pairs and assumed that all UZ pairs were MZ pairs, this would result in $45(28+17)$ MZ pairs of the 206 pairs. If this was the case, the observed proportion of MZ pairs was $(45 / 206)=0.22(95 \%$ CI [0.16, $0.28])$, whereas the expected proportion of $\mathrm{MZ}$ was $(66 / 206)$ $=0.32(95 \% \mathrm{CI}[0.26,0.39]), p$ value $<.02$, showing that even in this extreme scenario, we still had too few MZ pairs in the sample.

Hospitalization Patterns of 67 Pairs in Which Only One Twin Had T21. Patterns of co-twins with normal karyotypes $(n=11)$ and no cytogenetic reports $(n=56)$ were alike and substantially different from individuals with T21, indicating that co-twins without a cytogenetic report were as healthy as co-twins with confirmed normal karyotypes. Exclusion of OS co-twins did not influence the results.

\section{Discussion}

\section{Major Findings}

On the basis of linkage between several nationwide registers, we identified all live-born twins diagnosed with chromosomal aberrations born in Denmark during 1968-2009 and compared the prevalence of chromosomal aberrations in twins versus singletons.

No overall difference in risk of chromosomal aberrations between twins and singletons was found, except for a significantly increased prevalence in twins born in the period of 2005-2009, and a tendency of an increase in prevalence among twins of mothers in the age group of 35-39 years.

In data stratified on zygosity, we saw a tendency of a lower risk of chromosomal aberrations in $\mathrm{MZ}$ twins, while the risk in DZ twins was comparable to that in singletons.

With regard to T21, no significant overall difference in the risk between twins and singletons was shown. However, a significantly increased risk of T21 was seen for twins in the maternal age group of 35-39 years, for twins born in 


\begin{tabular}{|c|c|c|c|c|c|}
\hline \multicolumn{6}{|c|}{$\begin{array}{l}\text { Zygosity by Questionnaires, Subsequent DNA-Based Zygosity Examinations and Concordance Status } \\
\text { With Regard to Karyotype in } 206 \text { Twin Pairs in Which at Least One Had a Chromosomal Aberration }\end{array}$} \\
\hline $\begin{array}{l}\text { Zygosity by } \\
\text { questionnaires, before } \\
\text { DNA examinations }\end{array}$ & $\begin{array}{l}\text { DNA-based } \\
\text { zygosity }\end{array}$ & $\begin{array}{l}\text { DNA not } \\
\text { available }\end{array}$ & $\begin{array}{l}\text { Concordant } \\
\text { karyotypes }\end{array}$ & $\begin{array}{l}\text { Only one } \\
\text { cytogenetic report }\end{array}$ & $\begin{array}{l}\text { Discordant } \\
\text { karyotypes }\end{array}$ \\
\hline & & & (\% of total in rows) & & \\
\hline \multirow[t]{2}{*}{ MZ: 15} & MZ: 9 & & 7 (78\%) & 2 (22\%) & 0 \\
\hline & & MZ: 6 & $3(50 \%)$ & $3(50 \%)$ & 0 \\
\hline \multirow[t]{3}{*}{ DZ: 63} & $M Z: 2$ & & $1(50 \%)$ & $1(50 \%)$ & 0 \\
\hline & DZ: 32 & & 0 & $21(66 \%)$ & $11(34 \%)$ \\
\hline & & DZ: 29 & 0 & $21(72 \%)$ & $8(28 \%)$ \\
\hline \multirow[t]{3}{*}{ UZ: 58} & MZ:11 & & $6(55 \%)$ & 5 (45\%) & 0 \\
\hline & DZ: 30 & & $1(3 \%)$ & $24(80 \%)$ & $5(17 \%)$ \\
\hline & & UZ: 17 & $4(23.5 \%)$ & $9(53 \%)$ & $4(23.5 \%)$ \\
\hline OS: $70^{a}$ & & & $4(6 \%)$ & 51 (73\%) & 15 (21\%) \\
\hline
\end{tabular}

Note: Year of birth: 1968-2009. MZ = monozygotic; DZ = same-sex dizygotic; UZ = uncertain zygosity; OS = opposite sex. aDNA-based zygosity examinations were not carried out in OS twins.

the period 2005-2009, and among DZ twins, whereas MZ twins seemed to have a tendency of a lower risk of T21.

The observed proportion of MZ pairs was significantly low in twin pairs with chromosomal aberrations whereas the proportion of $\mathrm{DZ}$ twins consequently was larger than expected.

\section{Results in Relation to Previous Studies}

In contrast to the present study, a consistent finding in many previous studies was a lower prevalence of T21 (Boyle et al., 2014; Doyle et al., 1991; Hay \& Wehrung, 1970; Kallen, 1986; Windham \& Bjerkedal, 1984) or chromosomal aberrations (Boyle et al., 2013) in twins. Boyle et al. (2014) assessed the risk of T21 stratified on zygosity and estimated the risk (of at least one child with T21) in MZ pregnancies to be one third of the risk in singleton pregnancies, whereas in $\mathrm{DZ}$ pregnancies, it was one third higher than in singleton pregnancies (i.e., lower than the generally expected doubling of risk).

Congruous with our results, other studies did not find a difference in risk of T21 (Li et al., 2003; Tang et al., 2006) or chromosomal aberrations (Glinianaia et al., 2008; Li et al., 2003; Tang et al., 2006) between twins and singletons. Several studies have pointed out that too few concordant SS pairs/MZ pairs were seen (compared to estimates from a theoretical distribution according to the Weinberg method (Boyle et al., 2013; Hay \& Wehrung, 1970) or compared to calculated rates from statistical reviews (McDonald, 1964). Kallen noticed a complete lack of concordant pairs (Kallen, 1986).

Risk estimates may differ between studies for a number of reasons. Lack of zygosity information was a major constraint in all studies, and concordant phenotypes in SS pairs were frequently used as a proxy for MZ twinning. When Boyle et al. (2014) assessed the risk of T21 separated on zygosity the proportions of $\mathrm{MZ}$ and $\mathrm{DZ}$ twins were calculated according to the Weinberg method - that is, based on esti- mates - and the results of these studies must be interpreted with caution. In addition, since the risk was calculated per pregnancy and not at the individual level, the results of these studies cannot be compared directly to the overall population prevalence (McGue, 1992). Variation may also partly be explained by differences in sample size, methods of case selection and inclusion criteria. Some studies were based on live-born children, whereas others included fetal deaths from 20 weeks of gestation and termination of pregnancy for fetal anomaly. In studies that included only live births, twin pregnancies with a fetal loss would either not be included or would be registered as singletons, which would lower the risk estimate in twins. A difference in the proportion of singleton versus twin pregnancies that proceeded to termination of pregnancy would also bias studies with only live births included.

Furthermore, a number of factors have changed over the years such as diagnostic methods and the possibility of earlier or more specific prenatal diagnosis, prenatal care, and treatment (e.g., of twin-twin transfusion syndrome), better neonatal survival, increased age of first-time mothers, the increase in number of twin births, and perhaps a general change in the way termination of pregnancy is perceived and practiced in society.

\section{Interpretation of the Present Results}

The higher risk of T21 that was seen in DZ twins might be explained by type 1 errors due to multiple testing or by a lower proportion of termination of pregnancy for fetal anomaly in multiple pregnancies (Boyle et al., 2013), that is, parents might have chosen not to proceed with selective feticide due to concerns for a healthy co-twin. Parents' age might also be positively related to a lower frequency of selective feticide or termination of pregnancy for fetal anomaly; for example, if the pregnancy was established by in vitro fertilization, which is often associated with higher age of the parents. This could partially explain the higher 
risk of T21 seen in twins born in the maternal age group of 35-39 years.

The introduction of a new screening method (Ekelund et al., 2008) at a national level for common trisomies in September 2004 increased antenatal detection rate and halved the number of infants born with trisomy 13, 18, and 21 (Ekelund et al., 2008; Ekelund et al., 2011). This might explain the drop in singletons born with chromosomal aberrations during 2005-2009, while termination of pregnancy for fetal anomaly in multiple births may have been unaffected, probably due to the considerations mentioned above.

A surplus of SS twins was seen among DZ twins, which could be due to multiple testing, although a similar pattern has been observed in other studies (James, 1992).

The tendency of a low risk of chromosomal aberrations in $\mathrm{MZ}$ twins along with the apparent lack of $\mathrm{MZ}$ pairs with chromosomal aberrations could partly be explained if most UZ pairs were truly MZ twins. This is, however, unlikely, since the pairwise concordance rate among UZ twins was only 0.38 . In general, misclassification was limited to a minimum in our study due to classification by questionnaires and DNA analyses. A more likely explanation is a true lack of MZ pairs with chromosomal aberrations, due to a selective and early loss of affected fetuses.

\section{The Present Results in Relation to Hall's Hypothesis}

An implication of Hall's hypothesis (Hall, 1996; 2003; Hall \& Lopez-Rangel, 1996) is a higher a priori risk of chromosomal aberrations in twins compared to singletons. Our PPR results on live-born children did not support an increased risk of chromosomal aberrations in MZ twins - by contrast, a tendency of a lower risk was found.

Another implication of the hypothesis is the expectation of MZ twins to be discordant (possibly in a mosaic state) for genetic aberrations. Our concordance rate for MZ twins is discussed below. In order to detect potential mosaicism in MZ twins with chromosomal aberrations, we will now carry out a clinical study.

\section{Probandwise Concordance Rates}

We found the probandwise concordance rate with regards to karyotype for MZ twins to be only 0.76 (95\% CI [0.60, 0.87]. Supported by hospitalization patterns of newborns with T21 and their co-twins, we assumed that pairs in which the co-twin had no cytogenetic report were discordant. Theoretically, however, karyotyping of a co-twin might have been omitted in case of similar phenotypes (in $11 \mathrm{MZ}$ pairs with DNA-verified zygosity in our cohort the co-twin had no cytogenetic report), and some pairs are probably incorrectly classified. However, the exact concordance rate of $\mathrm{MZ}$ pairs also depends on the true distribution of UZ pairs and could therefore be both higher and lower than our estimate.

\section{Strengths and Limitations}

The main limitation of our study was the inclusion of only live-born children, since a selective loss of fetuses in twins or singletons would lead to bias. There might be a high number of twin pregnancies with chromosomal aberrations at conception. However, selective loss of one or both twin fetuses would lower the risk of live-born twins with chromosomal aberrations. Twin pregnancies with unrecognized loss of only one fetus would result in live-born singletons and, depending on their chromosomal status, lead to a lower or higher risk estimate in singletons. The less likely scenario of selective loss of singleton fetuses with chromosomal aberrations would give a higher risk estimate in twins.

A potential limitation is the lack of zygosity classification by DNA methods in all twin pairs.

The major strength of our study is the availability of reliable data from several databases with national coverage and the ability to link data across those databases. Our cohort is therefore unselected and has a national coverage of the subject. In addition, our study on the relative risk of chromosomal aberrations in $\mathrm{MZ}$ and $\mathrm{DZ}$ twins versus singletons is, to our knowledge, the first of its kind with zygosity status of twin pairs with chromosomal aberrations being based on DNA examinations. Finally, our risk estimates can be compared directly to the overall population prevalence, as they are calculated at the individual level.

To summarize, our data showed no difference in risk of chromosomal aberrations between twins and singletons. However, the proportion of $\mathrm{MZ}$ pairs with chromosomal aberrations was significantly lower than expected. Furthermore, a tendency of a relative low risk of T21 among MZ twins was seen. A unifying explanation of these patterns could be that twins around conception actually may have an increased risk of chromosomal aberrations, but increased fetal mortality among especially MZ twins leads to no difference in risk among live-born twins and singletons.

\section{Authors' Contribution}

Conception or design of the work: L. Kroeldrup, J. M. Hertz, C. Fagerberg, K. Christensen. Data acquisition, analysis, and interpretation: L. Kroeldrup, L. A. Larsen, C. Fagerberg, J. M. Hertz, K. Christensen. Drafting of the manuscript: L. Kroeldrup, L. A. Larsen, K. Christensen. Drafting of figures and tables: L. Kroeldrup, L. A. Larsen, K. Christensen. Critical review and final approval of the manuscript: all authors.

\section{Acknowledgments}

The authors thank Steen Gregersen for technical assistance and Jan Hansen at DCCR for continuing support. A special thanks to the late Mads Hollegaard at The NBSBiobank, SSI, for his engagement, competent technical support and for readily facilitating the collection of DNA samples. This work was supported by the University of Southern 
Denmark; Region of Southern Denmark; Aase and Ejnar Danielsen Foundation; and A. P. Moeller and Wife Chastine Mc-Kinney Moeller's Foundation.

\section{Conflict of Interest}

None.

\section{Ethical Standards}

All procedures contributing to this work was approved by and comply with the ethical standards of the Danish Data Protection Agency (ID: 2012-41-0112) and the Scientific-Ethical Committee of Southern Denmark (ID: S20130037).

\section{References}

Abel, E. L., \& Kruger, M. L. (2012). Maternal and paternal age and twinning in the United States, 2004-2008. Journal of Perinatal Medicine, 40, 237-239.

Boyle, B., McConkey, R., Garne, E., Loane, M., Addor, M. C., Bakker, M. K., ... Dolk, H. (2013). Trends in the prevalence, risk and pregnancy outcome of multiple births with congenital anomaly: A registry-based study in 14 European countries 1984-2007. BJOG: An International Journal of Obstetrics and Gynaecology, 120, 707-716.

Boyle, B., Morris, J. K., McConkey, R., Garne, E., Loane, M., Addor, M. C., ... Dolk, H. (2014). Prevalence and risk of Down syndrome in monozygotic and dizygotic multiple pregnancies in Europe: Implications for prenatal screening. BJOG: An International Journal of Obstetrics and Gynaecology, 121, 809-819; discussion 820.

Christiansen, L., Frederiksen, H., Schousboe, K., Skytthe, A., von Wurmb-Schwark, N., Christensen, K., \& Kyvik, K. (2003). Age- and sex-differences in the validity of questionnaire-based zygosity in twins. Twin Research, 6, 275-278.

D’Antonio, F., Khalil, A., Dias, T., \& Thilaganathan, B. (2013). Early fetal loss in monochorionic and dichorionic twin pregnancies: Analysis of the Southwest Thames Obstetric Research Collaborative (STORK) multiple pregnancy cohort. Ultrasound in Obstetrics and Gynecology, 41, 632-636.

Doyle, P. E., Beral, V., Botting, B., \& Wale, C. J. (1991). Congenital malformations in twins in England and Wales. Journal of Epidemiology and Community Health, 45, 43-48.

Ekelund, C. K., Jorgensen, F. S., Petersen, O. B., Sundberg, K., \& Tabor, A. (2008). Impact of a new national screening policy for Down's syndrome in Denmark: Population based cohort study. British Medical Journal, 337, a2547.

Ekelund, C. K., Petersen, O. B., Skibsted, L., Kjaergaard, S., Vogel, I., \& Tabor, A. (2011). First-trimester screening for trisomy 21 in Denmark: Implications for detection and birth rates of trisomy 18 and trisomy 13. Ultrasound in $\mathrm{Ob}$ stetrics and Gynecology, 38, 140-144.

Fellman, J., \& Eriksson, A. W. (2006). Weinberg's differential rule reconsidered. Human Biology, 78, 253-275.
Gardner, R. J. M., Sutherland, G. R., \& Shaffer, L. G. (2012). Chromosome abnormalities and genetic counselling (4th ed.). New York: Oxford.

Glinianaia, S. V., Rankin, J., \& Wright, C. (2008). Congenital anomalies in twins: A register-based study. Human Reproduction, 23, 1306-1311.

Goddijn, M., \& Leschot, N. J. (2000). Genetic aspects of miscarriage. Bailliere's Best Practice \& Research: Clinical Obstetrics \& Gynaecology, 14, 855-865.

Hall, J. G. (1996). Twinning: Mechanisms and genetic implications. Current Opinion in Genetics and Development, 6, 343-347.

Hall, J. G. (2003). Twinning. Lancet, 362, 735-743

Hall, J. G., \& Lopez-Rangel, E. (1996). Embryologic development and monozygotic twinning. Acta Geneticae Medicae et Gemellologiae, 45, 53-57.

Harvald, B., Hauge, G., Kyvik, K. O., Christensen, K., Skytthe, A., \& Holm, N. V. (2004). The Danish Twin Registry: Past and present. Twin Research, 7, 318-335.

Hassold, T., \& Chiu, D. (1985). Maternal age-specific rates of numerical chromosome abnormalities with special reference to trisomy. Human Genetics, 70, 11-17.

Hassold, T. J., \& Jacobs, P. A. (1984). Trisomy in man. Annual Review of Genetics, 18, 69-97.

Hay, S., \& Wehrung, D. A. (1970). Congenital malformations in twins. American Journal of Human Genetics, 22, 662-678.

Herskind, A. M., Almind Pedersen, D., \& Christensen, K. (2013). Increased prevalence of congenital heart defects in monozygotic and dizygotic twins. Circulation, 128, 11821188.

James, W. H. (1992). The current status of Weinberg's differential rule. Acta Geneticae Medicae et Gemellologiae, 41, 33 42.

Kallen, B. (1986). Congenital malformations in twins: A population study. Acta Geneticae Medicae et Gemellologiae, 35, 167-178.

Li, S. J., Ford, N., Meister, K., \& Bodurtha, J. (2003). Increased risk of birth defects among children from multiple births. Birth Defects Research. Part A: Clinical and Molecular Teratology, 67, 879-885.

Ljunger, E., Cnattingius, S., Lundin, C., \& Anneren, G. (2005). Chromosomal anomalies in first-trimester miscarriages. Acta Obstetricia et Gynecologica Scandinavica, 84, 11031107.

Lynge, E., Sandegaard, J. L., \& Rebolj, M. (2011). The Danish National Patient Register. Scandinavian Journal of Public Health, 39(Suppl.), 30-33.

Machin, G. A. (1996). Some causes of genotypic and phenotypic discordance in monozygotic twin pairs. American Journal of Medical Genetics, 61, 216-228.

McDonald, A. D. (1964). Mongolism in twins. Journal of Medical Genetics, 1, 39-41.

McGue, M. (1992). When assessing twin concordance, use the probandwise not the pairwise rate. Schizophrenia Bulletin, $18,171-176$.

Norgaard-Pedersen, B., \& Hougaard, D. M. (2007). Storage policies and use of the Danish Newborn 
Screening Biobank. Journal of Inherited Metabolic Disease, 30, 530-536.

Oldenburg, A., Rode, L., Bodker, B., Ersbak, V., Holmskov, A., Jorgensen, F. S., ... Tabor, A. (2012). Influence of chorionicity on perinatal outcome in a large cohort of Danish twin pregnancies. Ultrasound in Obstetrics and Gynecology, 39, 69-74.

Pedersen, C. B. (2011). The Danish Civil Registration System. Scandinavian Journal of Public Health, 39(Suppl.), 22-25.

Rydhstroem, H., \& Heraib, F. (2001). Gestational duration, and fetal and infant mortality for twins vs singletons. Twin Research, 4, 227-231.

Sieberts, S. K., Wijsman, E. M., \& Thompson, E. A. (2002). Relationship inference from trios of individuals, in the presence of typing error. American Journal of Human Genetics, 70, 170-180.

Simpson, J. L. (2007). Causes of fetal wastage. Clinical Obstetrics and Gynecology, 50, 10-30.

Skytthe, A., Kyvik, K., Holm, N. V., Vaupel, J. W., \& Christensen, K. (2002). The Danish Twin Registry: 127 birth cohorts of twins. Twin Research, 5, 352-357.

Skytthe, A., Kyvik, K. O., Holm, N. V., \& Christensen, K. (2011). The Danish Twin Registry. Scandinavian Journal of Public Health, 39(Suppl.), 75-78.

Tang, Y., Ma, C. X., Cui, W., Chang, V., Ariet, M., Morse, S. B., ... Roth, J. (2006). The risk of birth defects in multiple births: A population-based study. Maternal and Child Health Journal, 10, 75-81.
Videbech, P., \& Nielsen, J. (1979). Electronic data processing in the Danish cytogenetic central register and EDP problems of registers in general. Clinical Genetics, 15, 137-146.

Windham, G. C., \& Bjerkedal, T. (1984). Malformations in twins and their siblings, Norway, 1967-79. Acta Geneticae Medicae et Gemellologiae, 33, 87-95.

Zwijnenburg, P. J., Meijers-Heijboer, H., \& Boomsma, D. I. (2010). Identical but not the same: The value of discordant monozygotic twins in genetic research. American Journal of Medical Genetics. Part B: Neuropsychiatric Genetics, 153B, 1134-1149.

\section{Appendix A}

Karyotypes in our data that we considered to be benign variants:

46,XYqh+; 46,XYqh-; 46,X,?Yqh-; 46,X,der(Y)?t(Y;15)(q11.2; p11); 46,XX,1qh+; 46,XX,9qh+; 46,XY,9qh+; 46,XY,9qh-; 46,XX,inv(9); 46,XY,inv(9); 46,XX,inv(9)(p13q21); 46,XY,inv(9) (p11q12); 46,XY,inv(9)(p11q13); 46,XX,inv(9),22ps+; 46,XY, $\operatorname{var}(15)(\mathrm{p} 13 \mathrm{QFQ} 55) ; 46, \mathrm{XX}, \operatorname{var}(16)(\mathrm{q} 11.2) ; 46, \mathrm{XY}, 16 \mathrm{qh}+; 46$, $\mathrm{XY}, \operatorname{var}(21)(\mathrm{QFQ} 35) ; 46, \mathrm{XY}, 21 \mathrm{ps}+; 46, \mathrm{XX}, 22 \mathrm{pss} ; 46, \mathrm{XY}, 22 \mathrm{pss}$; 46,XX,22ps+; 46,XY,22ps+.

\section{Appendix B}

Microsatellite markers used for zygosity analyses:

D10S1225, D8S1132, D1S518, D2S1384, D16S518, D18S1153,

D21S1912, D5S1505, D20S471, D11S4102, D4S394, and D6S309. 